\title{
Experimental study on specific grinding energy and particle size distribution of maize grain, stover and cob
}

\author{
Jun Fu ${ }^{1,2,3}$, Zhao Xue ${ }^{1,2}$, Zhi Chen ${ }^{2,3^{*}}$, Luquan Ren ${ }^{1,2}$ \\ (1. Key Laboratory of Bionic Engineering, Ministry of Education, Jilin University, Changchun 130022, China; \\ 2. College of Biological and Agricultural Engineering, Jilin University, Changchun 130022, China; \\ 3. Chinese Academy of Agricultural Mechanization Sciences, Beijing 100083, China)
}

\begin{abstract}
Reducing the particle size of biomass is of great significance for rational and efficient utilization of biomass. In this study, maize grain, stover, and cob were comminuted at different speeds (2000-2800 r/min) by hammer mill with a mesh size of $2.8 \mathrm{~mm}$. The mechanical energy for smashing three selected samples was obtained directly through the sensor and data testing system. Experimental results demonstrated that the maize cob had the highest total specific energy while the maize grain had the lowest (135.83-181.10 kW.h/t and 27.08-36.23 kW.h/t, respectively). In addition, for the same material, higher hammer mill speed generated more specific energy consumption. And the effective specific energy of maize stover had a similar trend to the total specific one. However, the effective specific grinding energy of maize cob and grain increased initially and then decreased with the increase of rotating speed. The fitting curves of the specific energy to mill speeds were determined, and the range of determination coefficients of the regression equation was 0.933-0.996. Particle size distribution curves were drawn by sieving the pulverized particles of the three samples based on a series of standard sieves. Fourteen relevant parameters characterizing the particle size distribution were calculated according to the screening data. Calculation results demonstrated that larger rotational speed leads to smaller particle sizes. Combining the size parameters, distribution parameters, and shape parameters, it was found that the distributions of the three samples all exhibit a distribution of "well-graded fine-skewed mesokurtic". The Rosin-Rammler function was considered to be suitable for characterizing the particle size distribution of maize grain, stover, and cob particles with a coefficient of determination between 0.930 and 0.992 .
\end{abstract}

Keywords: maize grain, maize stover, maize cob, specific energy, particle size distribution, comminution DOI: $10.25165 /$ j.ijabe. 20201304.5327

Citation: Fu J, Xue Z, Chen Z, Ren L Q. Experimental study on specific grinding energy and particle size distribution of maize grain, stover and cob. Int J Agric \& Biol Eng, 2020; 13(4): 135-142.

\section{Introduction}

Maize was the largest planted agricultural crop in China, and the yield ranked second in the world. Maize, composed of grain, stover, cob and the like, is the main economic and feed crop ${ }^{[1,2]}$. Among them, maize grain was not only one of the most important foodstuffs but also could be used in industrial production such as fuel, feed and other energy products. Maize stover and maize cob, as by-products of maize, were major sources of lignocellulosic biomass, which can be used for fuel, fertilizer, feed and energy production $^{[3,4]}$. In addition, as a type of renewable and clean energy, the utilization of fuel production could effectively reduce the use of fossil fuels and greenhouse gas emissions ${ }^{[5]}$. Therefore, the rational use of maize grain, stover, and cob was of great significance for the full utilization of maize, and will also bring ecological and economic benefits ${ }^{[6]}$. However, direct use of those samples could lead to a series of problems in storage, transportation, handling and processing ${ }^{[1]}$. Therefore, the biomass needs to be

\section{Received date: 2019-08-11 Accepted date: 2020-05-18}

Biographies: Jun Fu, PhD, Professor, research interests: bionic harvesting technology and equipment of grain, Email: fu_jun@jlu.edu.cn; Zhao Xue, PhD candidate, research interests: modern agricultural equipment technology, Email: xuezhao18@mails.jlu.edu.cn; Luquan Ren, Professor, Academician of Chinese Academy of Sciences, research interests: agricultural mechanization engineering, Email: lqren@jlu.edu.cn.

*Corresponding author: Zhi Chen, $\mathrm{PhD}$, Professor, research interests: grain harvesting technology and equipment. Chinese Academy of Agricultural Mechanization Sciences, Beijing 100083, China. Tel: +86-10-82688715, Email: caamschen@126.com pretreated.

Particle size reduction was a critical pre-treatment process for biomass use, which may generate new surface area, increase porosity and bulk density, and improve flow properties ${ }^{[7]}$. Moreover, pretreatment could also improve its digestibility and the accessibility of the enzymes to increase conversion and yield ${ }^{[8,9]}$. Mechanical power was required to overcome friction resistance and destroy the structure of biomass in the process of the biomass size reduction ${ }^{[10]}$. Ghorbani et al. ${ }^{[1]}$ pointed out that the measurement of smashing energy was very useful to lessen input power during bio-energy conversion. Therefore, studying the energy for grinding was very necessary for biomass conversion. The hammer mill was usually used for pretreatment because it was inexpensive, easy to operate and could produce various particle size and distributions. However, crushing or reducing size was an energy-intensive process, which had a significant impact on raw feedstock costs. Gil et al. ${ }^{[8]}$ also reported that grain size had a critical impact on the energy conversion technique. Hence, analyzing the grinding energy consumption of different maize products and the size distribution of crushed grain were important for the downstream processing.

Energy consumption of grinding biomass was affected by many factors, such as initial particle size, moisture content, material properties, feed quantity, and machine variables ${ }^{[12]}$. Soucek et al. ${ }^{[13]}$ reported that energy consumption increased from $53.0 \mathrm{~kW} \cdot \mathrm{h} / \mathrm{t}$ to $232.0 \mathrm{~kW} \cdot \mathrm{h} / \mathrm{t}$ as the moisture content of various forest residues and agricultural straws increased from $9.2 \%$ to $19.6 \%$. Mani et al. ${ }^{[14]}$ followed that effective energy of hammer mill (with $3.2 \mathrm{~mm}$ screen) for grinding switchgrass was the highest 
while grinding maize stover was the least. They also reported that with decreasing particle size, there was an increase of specific energy. Himmel et al. ${ }^{[15]}$ found the smaller the sieve size, the fewer the wheat straw particles retained on 60 mesh screen, indicating that the distribution curve was skewed to the finer granularity. Gil et al. ${ }^{[8]}$ studied particle and cumulative size distributions of poplar and maize straw, which were showed by the log-normal plots. In addition, they found that as mathematically expected, the value of the median diameter is always larger than the geometric mean diameter due to the fine distribution skewed. Brita et al. ${ }^{[9]}$ pointed out that the total specific energy for grinding three biomass samples increased as hammer mill speed increased. Additionally, they reported that 'well-grade fine-skewed mesokurtic' particles were produced by grinding. Mani et al. ${ }^{[14]}$ pointed out that the distribution curve of wheat grinds liked those of maize stover ${ }^{[15]}$, wheat straw, and alfalfa grinds ${ }^{[16]}$.

In previous studies, the energy consumption of grinding was obtained by taking various measurements ${ }^{[11]}$. Himmel et al. ${ }^{[15]}$ used the wattmeter to measure the total specific energy without considering the efficiency of the motor. Arthur et al. ${ }^{[17]}$ indirectly obtained the total specific energy by measuring the fuel consumption rate of the engine, without considering the energy conversion of the internal combustion engine. Naimi et al. ${ }^{[18]}$ studied the factors affecting the energy requirements of ground biomass and developed mechanical model equations to predict the energy input of the mill to achieve a specific particle size. It was found that most of the researches used indirect methods to measure energy consumption. Indirect measurement was not only difficult to operate, but also had large error. Therefore, it was necessary to use a new method to measure grinding energy consumption.

This study aimed to: (1) Determine the specific grinding energy of maize grain, stover, and cob by directly measuring the energy of the input to hammer mill, establish the polynomial equations between specific energy and mill speed, thereby improving the efficiency and reducing the overall process energy cost; (2) Study the distribution of grain size of maize grain, stover and cob, respectively, and provide data reference for the full value utilization of maize; and (3) Evaluate the particle size distribution of biomass in combination with empirical equations based on the data of sieving.

\section{Materials and methods}

\subsection{Samples preparation}

Three samples were used for the experiments: maize grain, stover, and cob (Figure 1). Maize samples were acquired from Jilin University Agricultural Experiment Base, China $\left(43^{\circ} 56^{\prime} 45.99^{\prime \prime} \mathrm{N}, 125^{\circ} 14^{\prime} 52.44^{\prime \prime} \mathrm{E}\right)$ in October 2018 and dried outdoors. Firstly, the maize ears were removed and subjected to threshing treatment, and the separated maize cob and maize grain were respectively used for subsequent experiments. Then the maize cob and maize stover were cut into $30-50 \mathrm{~mm}$ long pieces (Figure 1) with a band saw. The average diameter of maize cob except the top was $26.4 \pm 0.01 \mathrm{~mm}$. The average taper of maize cob top was $6.1^{\circ}$, and its average bottom diameter was $23.2 \pm$

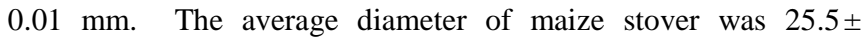
$0.01 \mathrm{~mm}$. Finally, maize grain, stover, and cob were placed in labeled transparent bags and grouped according to the test protocol. And the samples of each group were weighed $( \pm 0.02 \mathrm{~g}$ accuracy) and recorded. In each experiment, maize grain, stover and cob were randomly weighed from each group, and their mass was about $400 \mathrm{~g}, 200 \mathrm{~g}$, and $100 \mathrm{~g}$, respectively. Among them, the weight of
100 maize grains was about $27 \mathrm{~g}$. The moisture content of maize grain, stover, and cob was measured to be $8.76 \%, 15.20 \%, 6.34 \%$ (wet basis), respectively, by comparing sample weight before and after drying at $(103 \pm 2)^{\circ} \mathrm{C}$ for $24 \mathrm{~h}^{[19]}$.

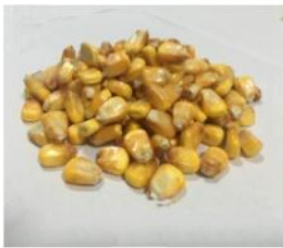

a. Maize grain

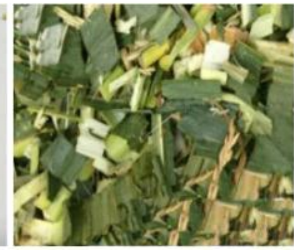

b. Maize stover

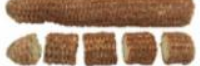

c. Maize cob
Figure 1 Samples of maize grain, stover, and cob

\subsection{Test apparatus and test procedures}

The test equipment used in this experiment consists of a power platform, a data test system and a hammer mill, as shown in Figures 2 and 3.

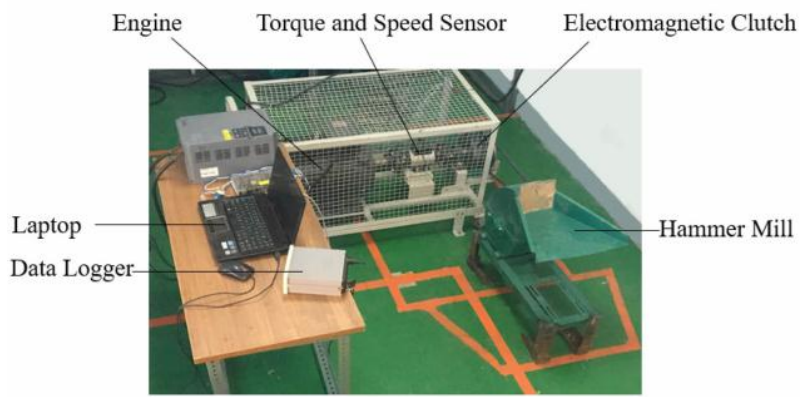

Figure 2 Flow diagram of test equipment

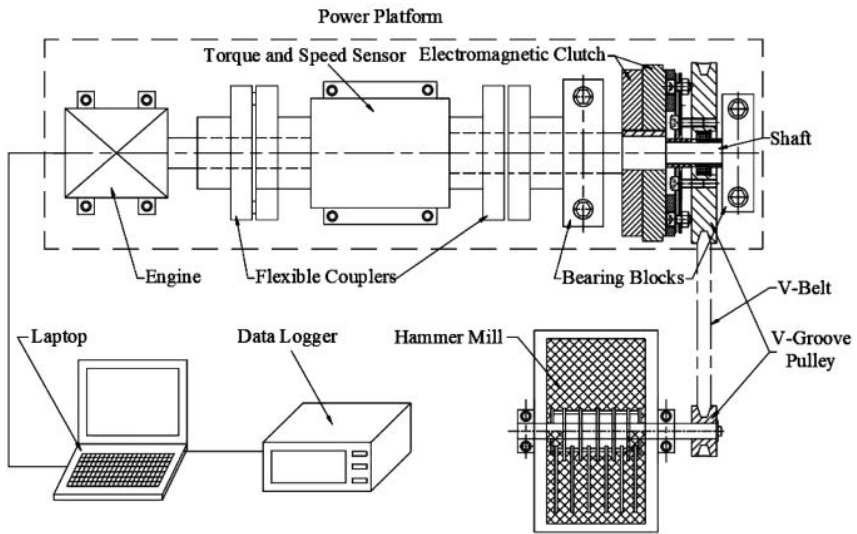

Figure 3 Schematic diagram of test equipment

Power was transmitted from the power platform to the hammer mill through the $\mathrm{V}$-belt drive. The engine and the drive shaft were connected by a coupling, and a torque and speed sensor $( \pm 0.08 \%)$ (CYB-803S/A500, Beijing Westzh Science and Technology Co., Ltd.) was mounted thereon (Figure 2). The sensor was connected to a data acquisition and processing module (Multichannel Measurement System, Westzh, 809I) and a laptop that could record torque and speed. During the stable operation of the machine, the raw data were continuously acquired for $90 \mathrm{~s}$, and then torque-time and speed-time data could be obtained by analysis. The hammer mill (9FZ-300, China) consisted of a rotor, a screen and other components. The rotor was composed of 24 hammers mounted on a rotating shaft with four pins on its periphery. Each hammer had a length of $72 \mathrm{~mm}$ and a thickness of $3 \mathrm{~mm}$. The screen installed around the rotor was replaceable and its aperture size was $2.8 \mathrm{~mm}$. The gap between the hammer and the screen was $6.4 \mathrm{~mm}$. An electromagnetic clutch was installed at the end of the drive shaft. This reduced the time and complexity requred for the test and also ensures the safety of the test. 
Before the experiment begins, the experiment samples were placed manually into the hammer mill, which could ensure that the test samples were shattered and reduce the generation of dust. After the grinding test, the biomass particles were collected in a storage bag for later sieving test. The sieve series were selected according to the range of particles in samples. Chinese series sieves that is numbered 8, 16, 24, 40, 70, 100, 140, and 200 (corresponding nominal sieve sizes: $2.5 \mathrm{~mm}, 1.25 \mathrm{~mm}, 0.85 \mathrm{~mm}$, $0.45 \mathrm{~mm}, 0.3 \mathrm{~mm}, 0.15 \mathrm{~mm}, 0.105 \mathrm{~mm}$, and $0.075 \mathrm{~mm}$, respectively) were used in this test. Figure 4 shows the grinds of maize grain, stover, and cob. Due to the different bulk densities, particle size analysis was carried out using $200 \mathrm{~g}$ of maize grain, $100 \mathrm{~g}$ of maize stover and $50 \mathrm{~g}$ of maize cob, respectively. Then, the mass of the particles remaining on each sieve after sieving was weighed $( \pm 0.02 \mathrm{~g})$ and recorded. Test was repeated three times. Finally, according to the standard, geometric mean diameter and geometric standard deviation were calculated.

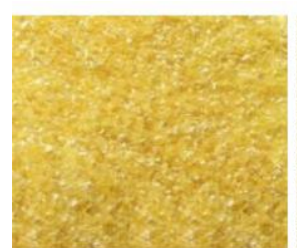

a. Maize grain

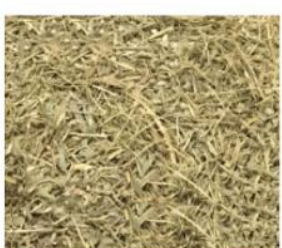

b. Maize stover

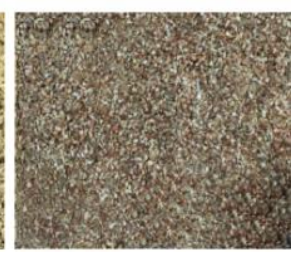

c.Maize cob
Figure 4 Grinds of maize grain, stover, and cob

\subsection{Data analysis}

Total energy consumption of grinding was obtained by integrating the power with the time. And total specific energy was expressed as the ratio of total energy to total mass. Then the effective specific energy was evaluated by effective power obtained by subtracting the no-load power from the total power ${ }^{[1,12]}$. The regression equations of specific energy were also fitted.

In this study, the Rosin-Rammler equation was applied to describe the distribution of ground maize grain, stover, and cob about their sizes. The Rosin-Rammler equation is given as:

$$
M_{c u}=100\left\{1-\exp \left[-\left(D_{p} / a\right)^{b}\right]\right\}
$$

where, $C_{u}$ was the cumulative percentage mass of undersized particles, $\% ; D_{p}$ was the particle size assumed to be equivalent to the diagonal of the sieve opening, mm; $a$ was the Rosin-Rammler size parameter, $\mathrm{mm}$; and $b$ was the Rosin-Rammler distribution parameter.

Also, fourteen parameters were calculated and divided into three groups: size parameters, shape parameters and distribution parameters. Among them, size parameters include: geometric mean diameter, median diameter and effective diameter; shape parameters include: skewness and kurtosis; distribution parameters include: geometric standard deviation, geometric standard deviation of high, low and total region, mass relative span, coefficient of uniformity, uniformity index, coefficient of gradation, and size guide number. These parameters was calculated based on the sieving data.

To further understand and explain the influence of test factors on test results, nonlinear regression fitting and variance analysis were performed.

\section{Results and discussion}

\subsection{Specific energy}

As shown in Figure 5, no-load power of operating the hammer mill increases from $(271.99 \pm 3.75) \mathrm{W}$ to $(378.41 \pm 2.29) \mathrm{W}$ with the speed increases from $2000 \mathrm{r} / \mathrm{min}$ to $2800 \mathrm{r} / \mathrm{min}$. The coefficient of determination of the no-load power equation is 0.997 , which means the equation fits very well.

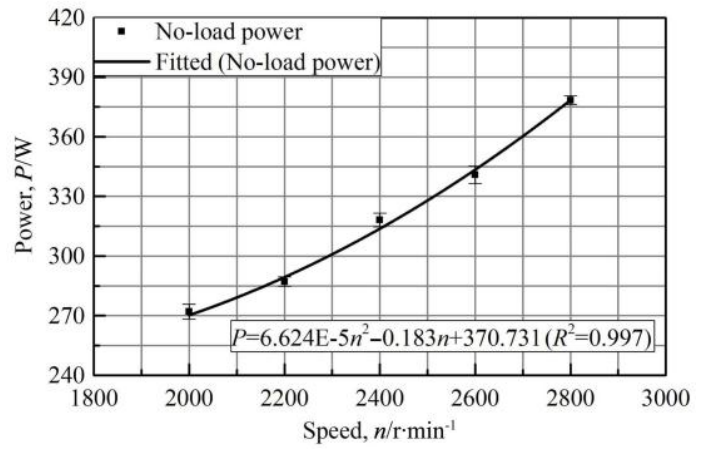

Figure 5 No-load power of the hammer mill as a function of speed

Figure 6 shows the total specific energy $\left(E_{t}\right)$ of grinding maize grain, stover, and cob at a rotating speed of 2000-2800 r/min by a hammer mill. There is a growth of total specific energy with the increasing speed. The reason for this phenomenon is that the increased speed will increase the energy requirement (no-load) for moving the mill rotor, and biomass particles that move freely along the screen increase the energy consumption. Maize cob consumes the highest total specific energy of $135.83-181.10 \mathrm{~kW} \cdot \mathrm{h} / \mathrm{t}$ as the hammer mill speed ranging 2000 to $2800 \mathrm{r} / \mathrm{min}$, while maize grain requires the least energy of $27.08-36.23 \mathrm{~kW} \cdot \mathrm{h} / \mathrm{t}$ among three biomass samples. The middle layer of the maize cob (the mid-cob called by Anazodo ${ }^{[20]}$ ) is particularly hard and it is not easy for size reduction. Therefore, grinding maize cob feedstock in the hammer mill requires the highest total specific energy, and the maize grain at the low moisture is equivalent to a brittle material that is easy to break, requires the least total specific energy for crushing. However, the total energy of maize stover is between maize cob and maize grain, because the straw contains less fiber and more sponge vascular tissues ${ }^{[12]}$. Datta ${ }^{[21]}$ reported that it took $18-24 \mathrm{MJ} / \mathrm{Mg}$ energy to break brittle materials like coal into 100-200 mesh sized particles. Bitra et al. ${ }^{[9]}$ found that the total specific energy for three biomass was $114.4 \mathrm{MJ} / \mathrm{Mg}, 125.1 \mathrm{MJ} / \mathrm{Mg}$, and 103.7 MJ/Mg respectively at $2000 \mathrm{r} / \mathrm{min}$. Therefore, it was found that because of the different fracture mechanisms, the crushing of lignocellulosic fibrous biomass materials requires higher energy than brittle materials.

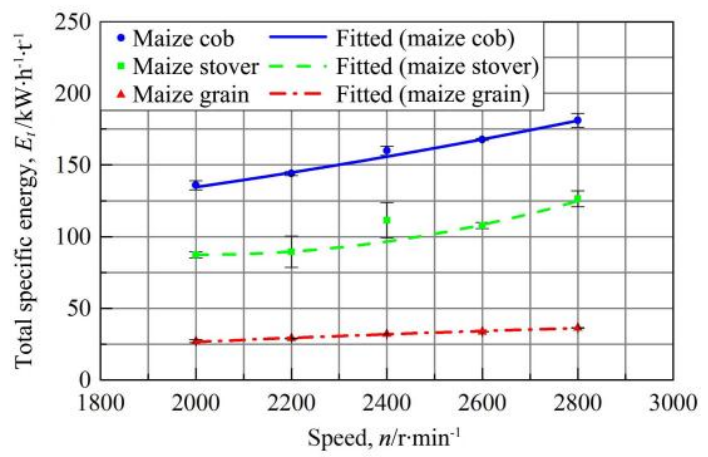

Figure 6 Total specific energy of grinding maize grain, stover, and cob at different speeds

Figure 7 shows the effective specific energy required to pulverize selected biomass at different speeds. The energy of maize cob and maize grain increases first and then decreases with increasing speed from $2000 \mathrm{r} / \mathrm{min}$ to $2800 \mathrm{r} / \mathrm{min}$. When the hammer mill rotates at a higher speed, the ground maize cob and maize grain can rapidly pass through the classifying screen, and 
less material were accumulated in the chamber because of higher centrifugal force. Therefore, the shear strength for grinding feedstock is reduced and the effective specific energy decreases. However, the effective energy consumption of maize stover increases by $73.8 \%$ from $20.88 \mathrm{~kW} \cdot \mathrm{h} / \mathrm{t}$ with the same increase in speed. It may be attributed to the residual maize stover filaments accumulated in the hammer mill chamber, making the hammer continues to hit and shear with them. Thus, the torque acting on the shaft of hammer mill increases and finally increases the effective specific energy. Hence, it was considered that the type of material and the speed of the hammer mill have an important influence on the effective specific energy.

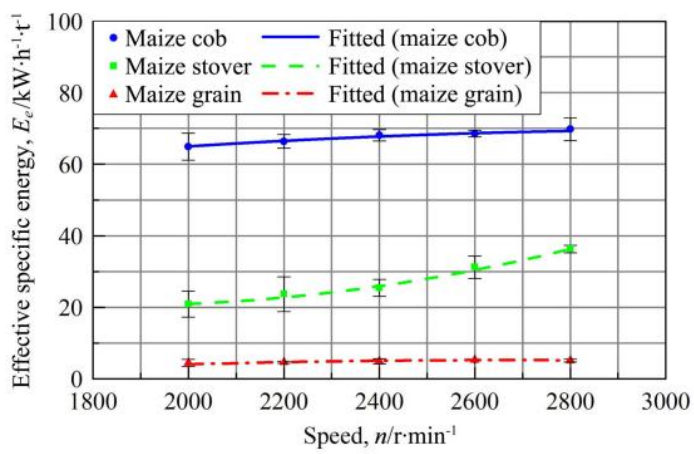

Figure 7 Effective specific energy of grinding maize grain, stover, and cob at different speeds

The polynomial relationships between $E_{t}$ and $E_{e}$ and hammer mill speeds of maize grain, stover, and cob are listed in Table 1. $R^{2}$ values of the second-order polynomial equations of maize grain, maize stover and maize cob are ranging from 0.933 to 0.996 , indicating that the equations were fitted very well.

Table 1 Polynomial relationship between total and effective specific energy of maize grain, stover and cob with speeds

\begin{tabular}{clcc}
\hline $\begin{array}{c}\text { Biomass } \\
\text { feedstock }\end{array}$ & \multicolumn{1}{c}{ Model } & $\begin{array}{c}\text { Speed } \\
\text { ranges } / \mathrm{r} \cdot \min ^{-1}\end{array}$ & $R^{2}$ \\
\hline \multirow{2}{*}{ Maize grain } & $E_{t}=-3.8045 \mathrm{E}-6 n^{2}+0.03027 n-18.8327$ & $2000 \leq n \leq 2800$ & 0.984 \\
& $E_{e}=-2.7219 \mathrm{E}-6 n^{2}+0.01448 n-14.0343$ & $2000 \leq n \leq 2800$ & 0.933 \\
Maize stover & $E_{t}=5.9907 \mathrm{E}-5 n^{2}-0.2408 n+3219.767$ & $2000 \leq n \leq 2800$ & 0.977 \\
& $E_{e}=1.7016 \mathrm{E}-5 n^{2}-0.06247 n+77.8125$ & $2000 \leq n \leq 2800$ & 0.996 \\
Maize cob & $E_{t}=1.2069 \mathrm{E}-5 n^{2}+3.2707 \mathrm{E}-5 n+86.2133$ & $2000 \leq n \leq 2800$ & 0.994 \\
& $E_{e}=-3.8119 \mathrm{E}-6 n^{2}+0.02368 n+32.8734$ & $2000 \leq n \leq 2800$ & 0.958 \\
\hline
\end{tabular}

Note: $E_{t}=$ Total specific energy $(\mathrm{kW} \cdot \mathrm{h} / \mathrm{t}), E_{e}=$ Effective specific energy $(\mathrm{kW} \cdot \mathrm{h} / \mathrm{t})$, $n=$ Speed $(\mathrm{r} / \mathrm{min})$.

\subsection{Particle size analysis}

\subsubsection{Particle size distribution}

Figures 8-10 show the distribution of the mass percentage of materials remained on each screen relative to the geometric average diameter. And the abscissa of the distribution is a logarithmic scale. It was found from the figures that there are significant differences in the log-normal distribution of maize grain, stover and cob pulverized particles. Also, for the same biomass, the distribution curve is different due to the change in the speed of the hammer mill. All the graphs depict that the curve is positively or finely skewed. This is because there are more small particles compared to biggish particles ${ }^{[22]}$. Similar results were also observed for ground biomass, for example, maize stover ${ }^{[9,15]}$, alfalfa $^{[16]}$, switchgrass, wheat, and barley straw ${ }^{[12]}$.

The mean inclusive graphic skewness, $G S_{i}$, can characterize asymmetry of the grain size distribution. As seen from Table 2, in all tests the values of the inclusive graphic skewness are between +0.1 and +0.3 , which means the particle size distributions for three biomass samples show a "fine skewed" ${ }^{\text {[23] }}$. However, there is no specific trend between skewness and hammer mill speed. Furthermore, for maize cob and maize grain, there is no significant difference between the values of $G S_{i}$ corresponding to different hammer mill speeds. The graphic kurtosis, $K_{g}$, is another shape parameter, used to measure the peakedness or flatness of a log-normal distribution. From Table $2, K_{g}$ presents values of 0.961 to 0.965 for maize stover, 0.960 to 0.967 for grain and 0.968 to 0.971 for maize cob.

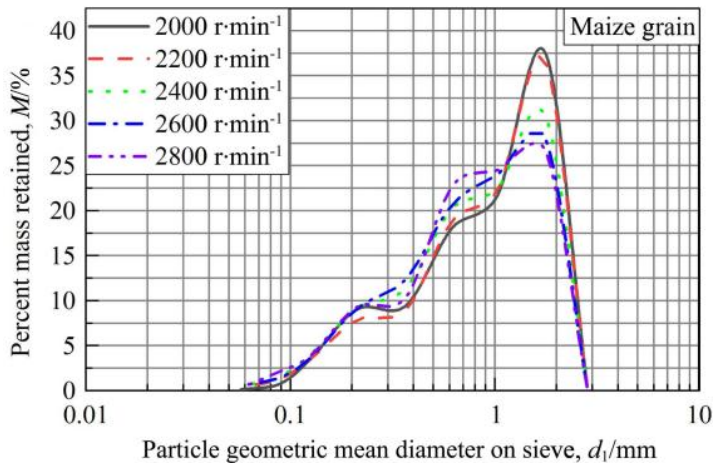

Figure 8 Log-normal particle size distribution of maize grain grinds at various speeds

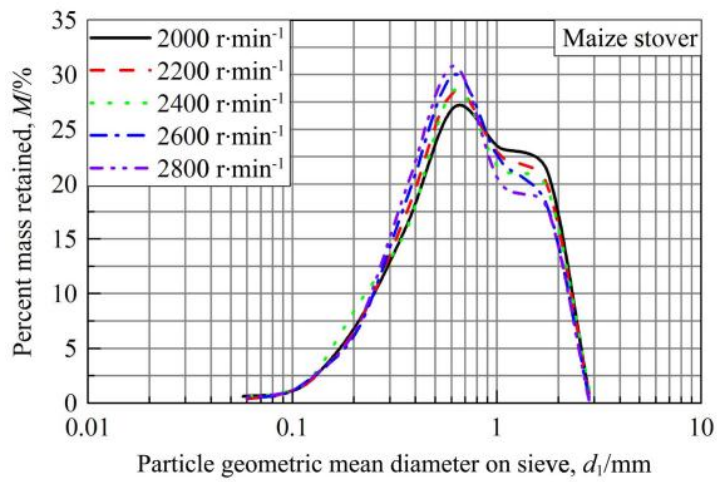

Figure 9 Log-normal particle size distribution of maize stover grinds at various speeds

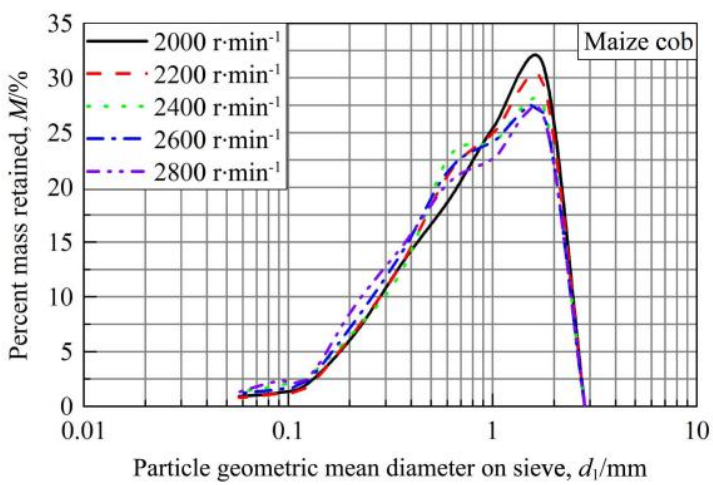

Figure 10 Log-normal particle size distribution of maize cob grinds at various speeds

However, there is no specific relationship between kurtosis and speeds. Folk ${ }^{[23]}$ pointed out that the values of kurtosis ranged from 0.90 to 1.11 represented that the particle size distribution was a 'mesokurtic' distribution (it had the same peak level of normal distribution). In this study, all values of $K_{g}$ are between 0.90-1.11 (Table 2). Therefore, the particle size distribution of maize grain, maize stover and maize cob grinds is a 'fine-skewed mesokurtic' distribution. Different hammer mill speeds have no significant influence on $G S_{i}$ and $K_{g}$ values of maize grain and maize cob $(p>0.05)$ but have a significant effect on maize stover $(p<0.05)$. 
The corresponding cumulative undersize mass curve is used to understand the relationship between cumulative undersize mass percentage and sieve aperture size (assume the same size as nominal mesh) (Figures 11-13). From these figures, it is observed that the distribution is continuously evolving without irregular changes or jumps. It is believed that the distributions of selected biomass for hammer mill at 2000-2800 r/min are 'well-graded distribution'. About 55\%, $70 \%$ and $58 \%$ of maize grain, maize stover and maize cob and grinds have a particle size of less than $1 \mathrm{~mm}$ for all speeds, which means that there are enough fine particles available for chemical reactions ${ }^{[18]}$.

\subsubsection{Size parameters}

The relationship between the average geometric mean diameter
$\left(X_{g m}\right)$ and hammer mill speeds for maize grain, stover, and cob grinds are shown in Figure 14. As seen from the graph, the geometric mean diameter of grinds decreases as speed increases. This result agrees with the report presented by Bitra et al. ${ }^{[9]}$ that the particle size of three biomass grinds decreased with increasing speed. Conversely, more coarse particles were obtained at low speed. Geometric average diameter of selected biomass grinds increases from $0.718,0.648$, and 0.686 to $0.832,0.699$, and 0.788 , respectively, as the speed decreases from $2800 \mathrm{r} / \mathrm{min}$ to $2000 \mathrm{r} / \mathrm{min}$ (Table 2). It is observed that at the same speed, $X_{g m}$ of maize grain grind is the largest while the maize stover grind is the smallest. It is attributed to the difference in the mechanical properties of three biomass.

Table 2 Size and shape parameters of maize grain, stover, and cob grinding by hammer mill with different speeds

\begin{tabular}{|c|c|c|c|c|c|c|c|}
\hline $\begin{array}{l}\text { Biomass } \\
\text { feedstock }\end{array}$ & $\begin{array}{l}\text { Mill speed, } \\
n / \mathrm{r} \cdot \min ^{-1}\end{array}$ & $\begin{array}{c}\text { Geometric mean } \\
\text { diameter, } X_{g m} / \mathrm{mm}\end{array}$ & $\begin{array}{c}\text { Median diameter, } \\
D_{50}{ }^{*} / \mathrm{mm}\end{array}$ & $\begin{array}{c}\text { Effective size, } \\
D_{10}{ }^{*} / \mathrm{mm}\end{array}$ & $\begin{array}{l}\text { Size guide number, } \\
N_{s g}{ }^{*}\end{array}$ & $\begin{array}{l}\text { Inclusive graphic } \\
\text { skewness, } G S_{i}^{*}\end{array}$ & $\begin{array}{c}\text { Graphic kurtosis, } \\
K_{g}{ }^{*}\end{array}$ \\
\hline \multirow{4}{*}{ Maize grain } & 2000 & $0.832 \mathrm{a}$ & $0.883 \mathrm{a}$ & $0.364 \mathrm{a}$ & $88.264 a$ & $0.132 \mathrm{a}$ & $0.960 \mathrm{a}$ \\
\hline & 2400 & $0.742 b$ & $0.801 b$ & $0.281 \mathrm{~b}$ & $80.076 \mathrm{~b}$ & $0.193 a$ & $0.967 \mathrm{a}$ \\
\hline & 2600 & $0.729 b$ & $0.792 b$ & $0.280 \mathrm{~b}$ & $79.190 \mathrm{~b}$ & $0.191 \mathrm{a}$ & $0.966 \mathrm{a}$ \\
\hline & 2800 & $0.718 b$ & $0.784 b$ & $0.288 \mathrm{~b}$ & $78.386 b$ & $0.177 \mathrm{a}$ & $0.965 \mathrm{a}$ \\
\hline \multirow{5}{*}{ Maize stover } & 2000 & $0.699 \mathrm{a}$ & $0.802 \mathrm{a}$ & $0.292 b$ & $80.243 a$ & $0.180 \mathrm{a}$ & $0.965 \mathrm{a}$ \\
\hline & 2200 & $0.691 \mathrm{a}$ & $0.807 \mathrm{a}$ & $0.320 \mathrm{a}$ & $80.697 a$ & $0.149 \mathrm{~b}$ & $0.961 b$ \\
\hline & 2400 & $0.673 b$ & $0.790 \mathrm{a}$ & $0.289 \mathrm{~b}$ & $79.010 \mathrm{a}$ & $0.179 \mathrm{a}$ & $0.965 \mathrm{a}$ \\
\hline & 2600 & $0.666 \mathrm{~b}$ & $0.775 \mathrm{a}$ & $0.302 \mathrm{ab}$ & $77.519 a$ & $0.158 \mathrm{ab}$ & $0.962 \mathrm{ab}$ \\
\hline & 2800 & $0.648 \mathrm{c}$ & $0.752 b$ & $0.290 \mathrm{~b}$ & $75.241 b$ & $0.159 \mathrm{ab}$ & $0.962 \mathrm{ab}$ \\
\hline \multirow{4}{*}{ Maize cob } & 2000 & $0.761 \mathrm{a}$ & $0.790 \mathrm{a}$ & $0.278 \mathrm{ab}$ & $78.982 \mathrm{a}$ & $0.205 \mathrm{a}$ & $0.967 \mathrm{a}$ \\
\hline & 2200 & $0.764 \mathrm{a}$ & $0.795 \mathrm{a}$ & $0.288 \mathrm{a}$ & $79.455 \mathrm{a}$ & $0.183 a$ & $0.961 \mathrm{a}$ \\
\hline & 2600 & $0.713 b$ & $0.736 \mathrm{ab}$ & $0.249 \mathrm{ab}$ & 73.609ab & $0.208 \mathrm{a}$ & $0.966 \mathrm{a}$ \\
\hline & 2800 & $0.669 \mathrm{c}$ & $0.700 \mathrm{~b}$ & $0.227 \mathrm{~b}$ & $69.985 b$ & $0.219 \mathrm{a}$ & $0.974 \mathrm{a}$ \\
\hline
\end{tabular}

Note:* indicates that the value of the same letter in each column is not significantly different at $p<0.05$. Values with different letters indicate that these values have significant differences.

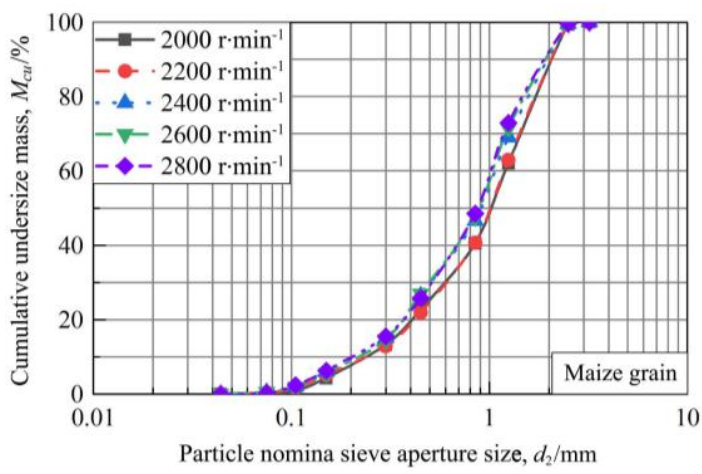

Figure 11 Cumulative percent undersize of maize grain particles at various speeds

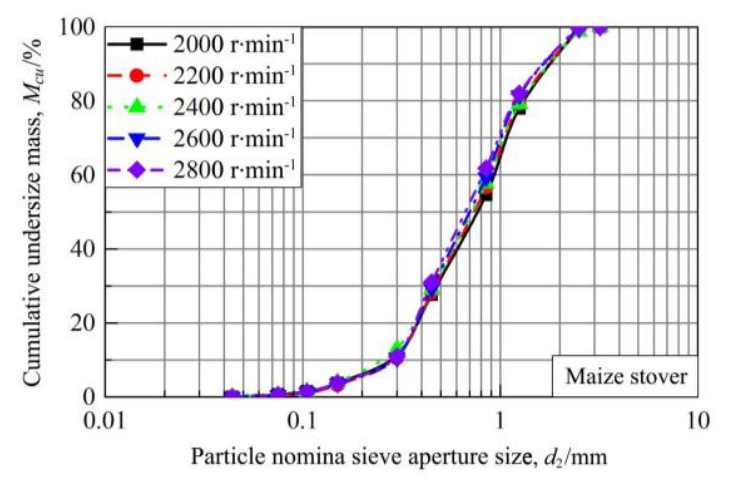

Figure 12 Cumulative percent undersize of maize stover particles at various speeds

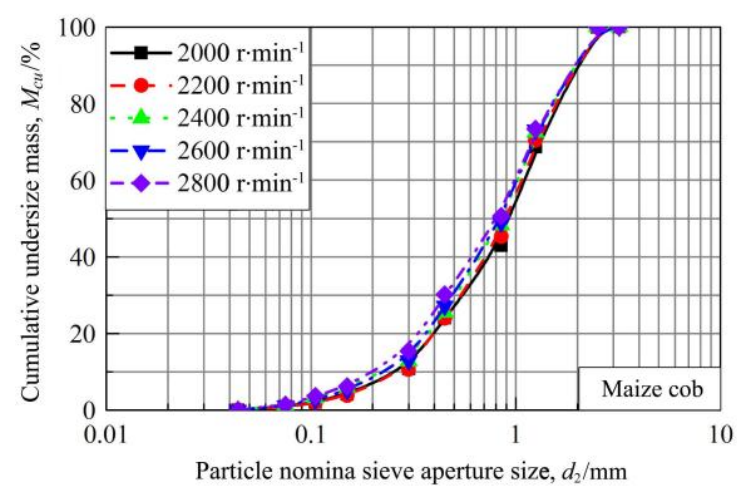

Figure 13 Cumulative percent undersize of maize cob particles at various speeds

Median diameter, $D_{50}$ (considered as the characteristic size), of maize grain, stover and cob are listed in Table 2. It is found that median diameter and hammer mill speed have similar trends to geometric mean diameter. Also, it is observed that $D_{50}$ is greater than $X_{g m}$ because of the fine skewness of the distribution. Effective size $\left(D_{10}\right)$ is a percentage representation of the distribution of fine fractions ${ }^{[8]}$. The rotational speed has a significant effect on it, which is similar to the median diameter and the geometric mean diameter. Generally, lower speed leads to larger particle sizes. From Table 2, it follows that the size guide number, $N_{s g}$, of maize grain, stover and cob decreases with an increase in speed. The trend is similar to the median diameter, which is because the value of the size number is obtained by 
multiplying the median diameter by 100 .

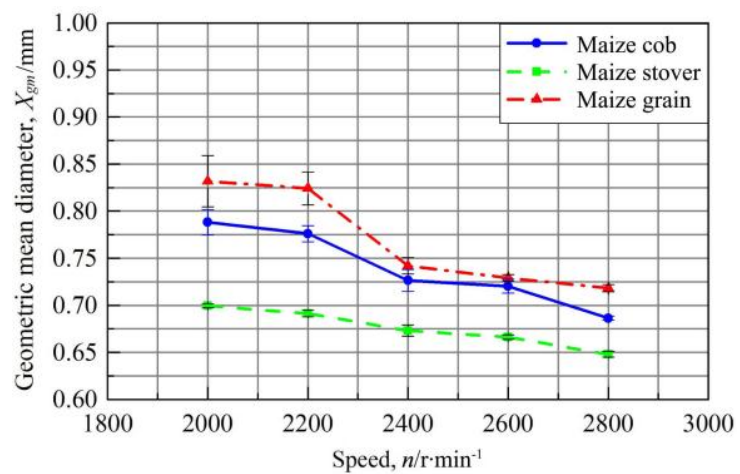

Figure 14 Variations of the geometric mean diameter of maize grain, stover, and cob at various speeds

\subsubsection{Dispersion parameters}

The geometric standard deviation $\left(S_{g m}\right)$ is one of the main distribution-related parameters used to describe the log-normal distribution. It is observed from Table 3 that $S_{g m}$ of pulverized particles of three samples obtained at all speeds are all greater than 1. Hinds ${ }^{[24]}$ reported that if the values of $S_{g m}$ were greater than or equal to 1.0 , comminuted particles of maize grain, stover and cob were a wide distribution. It is seen that the geometric standard deviation of maize stalks is at least 2.038 to 2.126 , while the geometric standard deviation of maize grain is at most 2.227 to 2.298. That means, among the three biomasses, the maize grain has the widest particle distribution, followed by the maize cob, while the maize stover has the narrowest particle size distribution. The ground particles of maize stover are relatively uniform while the uniformity of maize grain is poor. However, there is no specific trend between the geometric standard deviation and the hammer mill speeds. This may be because the fracture of lignocellulosic biomass is unpredictable.

$G S D_{1}, G S D_{2}$, and $G S D_{12}$ are used to analyze the dispersion of coarse, fine, and total particles, respectively. In Table 3, the values of $G S D_{2}$ are larger than $G S D_{1}$, which means the $G S D_{2}$ presents a higher average dispersion than $G S D_{1}$. Therefore, the fine particles are more than the coarse ones, so that the distribution is finely skewed. This is why $X_{g m}$ is always greater than $D_{50}$ in all cases. However, there is no established relationship between hammer mill speeds and the value of $G S D_{1}, G S D_{2}$ and $G S D_{12}$.

The mean mass relative span, $R S_{m}$, of maize grain, stover and cob does not form the specific relationship with hammer mill speeds (Table 3). However, maize cob has the largest values of the relative span among the three samples, which represents the maize cob particles have the widest distribution. That means, higher span leads to more heterogeneous particle size. In addition, from Table 2 and Table 3, the larger the relative span, the larger the skewness. Also, $R S_{m}$ is inversely proportional to the distribution parameter $(b)$ of the Rosin-Rammler equation. In this study, the relative span of the three biomasses was all larger than 1.0, which indicates that it is wide distribution. Brita et al. ${ }^{[9]}$ had similar results in the study of wheat straw, switchgrass and maize stover.

The uniformity index, $I_{u}$, of maize grain, stover and cob change irregularly with an increase in speeds from $2000 \mathrm{r} / \mathrm{min}$ to 2800 $\mathrm{r} / \mathrm{min}$ (Table 3). However, it can be observed that the uniformity index is inversely proportional to the relative span and skewness for all biomass materials. Moreover, the value of the uniformity index is very low, less than $20 \%$, possibly because the particle distribution is skewed or finely skewed. The uniformity coefficient $\left(C_{u}\right)$ indicates the uniformity of the particle size after grinding, and its values are generally greater than 1.0. Also, when the $C_{u}$ value is closer to 1.0 , the particles become more uniform. It is observed from Table 3 that the values of the uniformity coefficients of all the tests are all greater than 1 and less than 4 , which means that the particles are uniformly mixed ${ }^{[25]}$. It represents a well-graded particle size distribution as shown in the cumulative distribution curve. There is no specific relationship between the uniformity coefficient of maize stover, grain and cob at different rotating speeds. But the uniformity coefficient and the uniformity index are inversely proportional. The coefficient of gradation, $C_{g}$, does not follow a certain trend with the increase of speeds (Table 3). Budhu ${ }^{[25]}$ pointed out that the grading coefficient ranged from 1 to 3 indicated a well-graded distribution. In this study, all the values of the coefficient of gradation are between 1-3, which indicates that all the particles of the test have a well-graded distribution. Different hammer mill speeds have no significant influence on $R S_{m}, I_{u}, C_{u}$ and $C_{g}$ values of maize grain and cob $(p>0.05)$, but have a significant effect on maize stover $(p<0.05)$.

Table 3 Values of the dispersion parameters of maize grain, stover, and cob grinds at various speeds

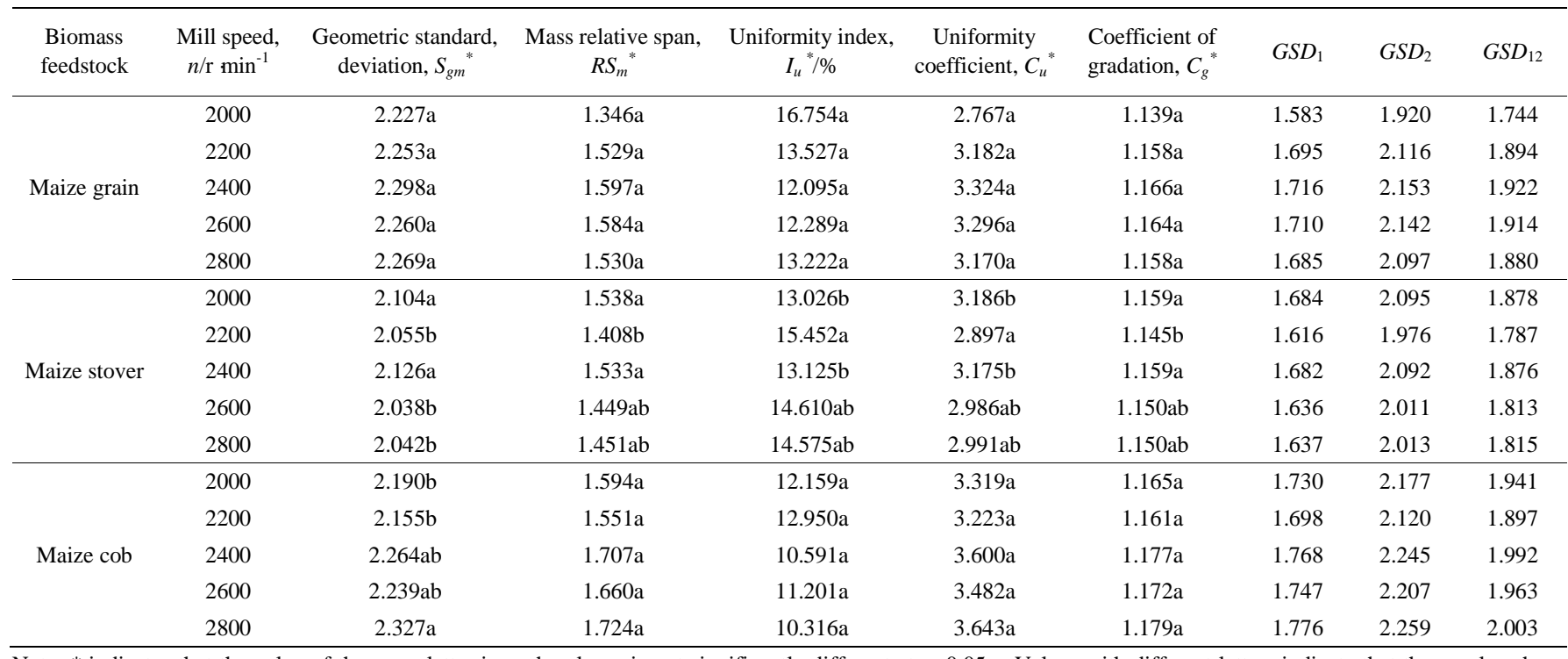

Note: * indicates that the value of the same letter in each column is not significantly different at $p<0.05$. Values with different letters indicate that these values have significant differences. 


\subsubsection{Rosin-Rammler function}

The Rosin-Rammler function, after years of use and research, is considered to be the best mathematical function for describing various particle size distributions. Typically, the distribution parameter $(b)$ and the size parameter $(a)$ are used to characterize the function. Table 4 lists the values of the coherent parameters for the equation.

Table 4 Related parameters and fitting coefficients of Rosin-Rammler equation of maize grain, stover, and cob at different speeds

\begin{tabular}{|c|c|c|c|c|}
\hline $\begin{array}{l}\text { Biomass } \\
\text { feedstock }\end{array}$ & $\begin{array}{l}\text { Mill speed, } \\
n / \mathrm{r} \cdot \min ^{-1}\end{array}$ & $\begin{array}{c}\text { Rosin-Rammler } \\
\text { size parameter, } \\
a^{*} / \mathrm{mm}\end{array}$ & $\begin{array}{c}\text { Rosin-Rammler } \\
\text { distribution } \\
\text { parameter, } b^{*} / \mathrm{mm}\end{array}$ & $\begin{array}{l}\text { Coefficient of } \\
\text { determination, } \\
R^{2}\end{array}$ \\
\hline \multirow{5}{*}{ Maize grain } & 2000 & $1.049 \mathrm{a}$ & $2.130 \mathrm{a}$ & 0.930 \\
\hline & 2200 & $1.052 \mathrm{a}$ & $1.902 \mathrm{a}$ & 0.965 \\
\hline & 2400 & $0.982 b$ & $1.801 \mathrm{a}$ & 0.966 \\
\hline & 2600 & $0.969 \mathrm{~b}$ & $1.815 \mathrm{a}$ & 0.975 \\
\hline & 2800 & $0.953 b$ & $1.880 \mathrm{a}$ & 0.946 \\
\hline \multirow{5}{*}{$\begin{array}{l}\text { Maize } \\
\text { stover }\end{array}$} & 2000 & $0.976 \mathrm{a}$ & $1.866 \mathrm{~b}$ & 0.992 \\
\hline & 2200 & $0.966 \mathrm{ab}$ & $2.037 \mathrm{a}$ & 0.980 \\
\hline & 2400 & $0.961 \mathrm{ab}$ & $1.873 \mathrm{~b}$ & 0.987 \\
\hline & 2600 & $0.941 \mathrm{~b}$ & $1.978 \mathrm{ab}$ & 0.989 \\
\hline & 2800 & $0.906 \mathrm{c}$ & $1.975 \mathrm{ab}$ & 0.990 \\
\hline \multirow{5}{*}{ Maize cob } & 2000 & $0.968 \mathrm{a}$ & $1.805 \mathrm{a}$ & 0.989 \\
\hline & 2200 & $0.968 \mathrm{a}$ & $1.861 \mathrm{a}$ & 0.991 \\
\hline & 2400 & $0.908 \mathrm{ab}$ & $1.694 \mathrm{a}$ & 0.981 \\
\hline & 2600 & $0.909 \mathrm{ab}$ & $1.738 \mathrm{a}$ & 0.988 \\
\hline & 2800 & $0.871 \mathrm{~b}$ & $1.675 \mathrm{a}$ & 0.981 \\
\hline
\end{tabular}

Note: $*$ indicates that the value of the same letter in each column is not significantly different at $p<0.05$. Values with different letters indicate that these values have significant differences.

The Rosin-Rammler distribution parameter, the slope of the distribution, of maize grain, stover, and cob (Table 4) at different speeds are determined. But there is no specific trend. The smaller the value of $b$, the lower the slope of the Rosin-Rammler equation, the wider the distribution there are (the larger the $R S_{m}$ ), resulting in a higher diversity of particle sizes. Table 2 and Table 4 show that as the distribution parameter increases and the kurtosis value gradually decreases, this signifies that the reduced distribution parameters represent a wider distribution range. Williams et al. ${ }^{[26]}$ reported that comminution resulted in an increase in the uniformity of the sample particles, which was the same as that expressed by the high values of $b . \quad R^{2}$ of maize cob and maize stover is greater than 0.98 , while the maize grain is greater than 0.930. This means that the Rosin-Rammler equations for the three biomasses fit very well. Similar trends have been reported in published studies ${ }^{[16,26]}$. The higher the coefficient of determination, the better the Rosin-Rammler function of maize cob particle size distribution is fitted. This is probably because Rosin-Rammler expression is ideal for a tilted particle size distribution. From Table 4, hammer mill speeds have no significant effect on Rosin-Rammler distribution parameters of maize grain and cob, while there is a significant effect on Rosin-Rammler distribution parameters of maize stover.

The Rosin-Rammler size parameter of selected samples gradually decreases as the speed increases from $2000 \mathrm{r} / \mathrm{min}$ to 2800 $\mathrm{r} /$ min (Table 4). The geometric mean diameter and the median diameter have the same trend. Moreover, it is observed that the value of the Rosin-Rammler size parameter is greater than $D_{50}$ and greater than $X_{g m}$ (Tables 2-4). The median diameter determined by the trend of the fitted curve, the geometric average diameter calculated from the linear portion of data points and the positive skew of the distribution curve lead to this trend ${ }^{[27]}$. As the value of $a$ increases, $D_{50}$ and $X_{g m}$ of the particles increase, which may be caused by the increasing amount of coarse particles and decreasing number of fine ones at low rotational speeds. For three biomass samples, hammer mill speeds have significant effects on Rosin-Rammler size parameters.

\section{Conclusions}

1) Maize cob had the highest total specific energy and maize grain had the lowest total specific energy $(135.83-181.10 \mathrm{~kW} \cdot \mathrm{h} / \mathrm{t}$, 27.08-36.23 kW.h/t). In addition, for the same material, the higher the hammer mill speed, the greater the total specific energy. Effective specific energy had a similar trend with the total specific one. However, the effective specific energy of cob and grain increased initially and then decreased with the increase of speed. This may be because of a large amount of straw filament remained in the mill chamber during the grinding process.

2) The particle size distribution curves of the samples were obtained based on sieving. And 14 related parameters were calculated to characterize the particle size distribution. The results showed that larger speed leads to smaller particle sizes. Through observing the size parameters, distribution parameters and shape parameters, it was found that the distributions of the three samples all exhibit a distribution of "well-graded fine-skewed mesokurtic".

3) Rosin-Rammler equation was very appropriate for characterizing the distribution of grain size of maize grain, stover, and cob particles with a coefficient of determination between 0.930-0.992.

Specific energy and distribution of grain size of maize grain, stover, and cob could offer key data support for improving the full value utilization of maize.

\section{Acknowledgements}

This work was financially supported by the National Natural Science Foundation of China (51705193) as well as the Science and Technology Development Project of Jilin Province (20170204016NY).

\section{[References]}

[1] Demiral İ, Eryazıcı A, Şensöz S. Bio-oil production from pyrolysis of corncob (Zea mays L.). Biomass and Bioenergy, 2012; 36: 43-49.

[2] Zhu H, Yue J, Li Z B, Zhang Z W. Multi-kernel dictionary learning for classifying maize varieties. Int J Agric \& Biol Eng, 2018; 11(3): 183-189.

[3] Wang L, Liu R H, Sun C, Cai W F, Tao Y W, Yin R Z, et al. Classification and comparison of physical and chemical properties of corn stalk from three regions in China. Int J Agric \& Biol Eng, 2014; 7(6): 98-106.

[4] Zhao P X, Cui F J, Bu L X, Jiang J X. Biogas production from microbial-alkali pretreated corn stover by solid-state anaerobic digestion. Int J Agric \& Biol Eng, 2015; 8(5): 96-104.

[5] Emami S, Tabil L G, Adapa P, George E, Tilay A, Dalai A, et al. Effect of fuel additives on agricultural straw pellet quality. Int J Agric \& Biol Eng, 2014; 7(2): 92-100.

[6] Yang W, Fu P, Yi W M. Catalytic fast pyrolysis of corn stover in a fluidized bed heated by hot flue gas: Physicochemical properties of bio-oil and its application. Int J Agric \& Biol Eng, 2017; 10(5): 226-233.

[7] Lisowski A, Kostrubiec M, Dąbrowska-Salwin M, Świętochowski A. The characteristics of shredded straw and hay biomass-Part 1-Whole Mixture. Waste and Biomass Valorization, 2018; 9(5): 853-859.

[8] Gil M, Arauzo I. Hammer mill operating and biomass physical conditions effects on particle size distribution of solid pulverized biofuels. Fuel 
Processing Technology, 2014; 127: 80-87.

[9] Bitra V S P, Womac A R, Chevanan N, Miu P I, Igathinathane C, Sokhansanj $\mathrm{S}$, et al. Direct mechanical energy measures of hammer mill comminution of switchgrass, wheat straw, and corn stover and analysis of their particle size distributions. Powder Technology, 2009; 193(1): 32-45.

[10] Pradhan P, Mahajani S M, Arora A. Production and utilization of fuel pellets from biomass: A review. Fuel Processing Technology, 2018; 181: 215-232.

[11] Ghorbani Z, Masoumi A A, Hemmat A. Specific energy consumption for reducing the size of alfalfa chops using a hammer mill. Biosystems Engineering, 2010; 105: 34-40

[12] Mani S, Tabil L G, Sokhansanj S. Grinding performance and physical properties of wheat and barley straws, corn stover and switchgrass. Biomass and Bioenergy, 2004; 27(4): 339-352.

[13] Soucek J, Hanzlikova I, Hutla P. A fine disintegration of plants suitable for composite biofuels production. Research Institute of Agricultural Engineering, 2003; 49: 7-11

[14] Mani S, Tabil L G, Sokhansanj S. Grinding performance and physical properties of selected biomass. In: American Society of Agricultural Engineers, St. Joseph, MI, 2002; pp.1-17.

[15] Himmel M, Tucker M, Baker J. Comminution of biomass: hammer and knife mills. Biotechnology and Bioengineering Symposium, 1985; 15: 39-58.

[16] Yang W, Sokhansanj S, Crerar W J, Rohani S. Size and shape related characteristics of alfalfa grind. Canadian Agricultural Engineering, 1996; 38(3): 201-205

[17] Arthur J F, Kepner R A, Dobie J B, Miller G E, Parsons P S. Tub grinder performance with crop and forest residues. Transactions of the ASAE,
1982; 25: 1488-1494.

[18] Naimi L J, Collard F, Bi X T, Lim C J, Sokhansanj S. Development of size reduction equations for calculating power input for grinding pine wood chips using hammer mill. Biomass Conversion and Biorefinery, 2016; 6: 397-405.

[19] ASABE Moisture measurement-forages. St. Joseph, MI: American Society of Agricultural and Biological Engineers, 2008; S358.2 Dec1988 (R2008)

[20] Anazodo U G N, Norris E R. Effects of genetic and cultural practices on the mechanical properties of corn cobs. J. Agric. Engng Res., 1981; 26: 97-107.

[21] Datta R. Energy requirement for lignocelluloses pretreatment process. Process Biochemistry, 1981; 16: 16-19.

[22] Esteban L S, Carrasco J E. Evaluation of different strategies for pulverization of forest biomasses. Powder Technology, 2006; 166(3): 139-151.

[23] Folk R L. Petrology of sedimentary rocks. Austin, Texas: Hemphill Publishing Company, 1974; 182p.

[24] Hinds W C. Aerosol technology: properties, behaviour, and measurement of airborne particles. John Wiley \& Sons, 1982; 465p.

[25] Budhu M. Soil Mechanics and foundations (with CD). John Wiley \& Sons, 2008; 656p.

[26] Williams O, Lester E, Kingman S, Giddings D, Lormor S, Eastwick C Benefits of dry comminution of biomass pellets in a knife mill. Biosystems Engineering, 2017; 160: 42-54.

[27] Perfect E, Xu Q, Terry D L. Improved parameterization of fertilizer particle size distribution. Journal of AOAC International, 1998; 81(5): 935-942. 